\title{
Study of Prolactin in Cervicovaginal Secretion in Women with Preterm Labor and Normal Pregnancy
}

\author{
Seema Mehrotra ${ }^{1}$, Urmila Singh ${ }^{2}$, Vandana Solanki ${ }^{3}$, SM Natu ${ }^{4}$, Shilpi Chauhan ${ }^{5}$, Ruchita Sharma ${ }^{6}$
}

\begin{abstract}
Objective: To evaluate the diagnostic value of cervicovaginal prolactin levels for predicting preterm delivery in women with preterm labor. Materials and methods: The preterm labor group and normal pregnancy group consisted of 75 and 150 patients between 24 weeks and 36 weeks of gestation. The preterm group was further subdivided into two groups. Study group la: patients who came up with preterm labor and given tocolytic but had preterm delivery $(n=50)$. Study group lb: patients who came up with preterm labor and given tocolytic and delivered full term $(n=25)$. A single cervicovaginal measurement was made in all the groups.

Results: Cervicovaginal prolactin was highest in the study group la $(11 \pm 9.31 \mathrm{ng} / \mathrm{mL})$ as compared to the study $\mathrm{group} \mathrm{lb}(4.61 \pm 6.2 \mathrm{ng} / \mathrm{mL})$ and control group $(2.51 \pm 5.1 \mathrm{ng} / \mathrm{mL})$, and the difference was statistically significant $(p=0.0311 ; p=0.0000)$. The optimal cut-off value of prolactin was greater than $7 \mathrm{ng} / \mathrm{mL}$ in study group la with sensitivity level of $78 \%$, at a specificity of $80 \%$ with positive and negative predictive values of $88.64 \%$ and $64.52 \%$, respectively. The area under the receiver operating characteristic (ROC) curve was $79 \%$ which indicates fair diagnostic accuracy of cervicovaginal prolactin in predicting preterm labor.

Conclusion: Prolactin is a potential biochemical marker which can be used alone or complementary to other markers for predicting preterm labor. Keywords: Cervicovaginal, Human chorionic gonadotropin, Preterm labor, Prolactin.

Journal of South Asian Federation of Obstetrics and Gynaecology (2020): 10.5005/jp-journals-10006-1758
\end{abstract}

\section{INTRODUCTION}

Preterm birth ( $<37$ weeks gestation) continues to be one of the most significant obstetrical problems in the world contributing to $28 \%$ of nonanomalous perinatal mortality ${ }^{1}$ and nearly half of all cases of congenital neurological disability. ${ }^{2,3}$ The burden of preterm birth is disproportionally distributed across the world with highest rates in Africa and Asia (31\% and 54\%, respectively). ${ }^{4}$ The incidence of preterm birth in India has been reported to be $14.5 \%{ }^{5}$

While our understanding of human labor and the causes of preterm labor have advanced over the past decades, the ability to accurately predict preterm labor has remained elusive. Apart from the history and clinical markers, a number of biochemical markers in various body fluids have been proposed for the prediction of preterm delivery. Plasma urocortin, fetal fibronectin, and phosphorylated insulin-like growth factor binding protein-1 and $\beta$-human chorionic gonadotropin (HCG) in cervicovaginal fluid have been shown to be a potential predictor in several studies. ${ }^{6-10}$ However, reported sensitivities, specificities, positive and negative predictive values have varied considerably in different studies and are far from optimal in same. ${ }^{10,11}$ Therefore, the search for the ideal marker is still on.

Prolactin is produced in the chorionic cytotrophoblast, decidua, amnion, and placental syncytiotrophoblast during pregnancy. ${ }^{12}$ Prolactin reaches its highest concentration in amniotic fluid $(7 \mu \mathrm{g} /$ $\mathrm{mL}$ ) during the second trimester and its concentration remains elevated throughout pregnancy. ${ }^{13,14}$ Prolactin can be considered as a possible marker for preterm birth for two reasons. (1) It is actively secreted by the decidua throughout gestation and (2) high concentrations are observed in the amniotic fluid. Therefore, prolactin in the vagina or at the external cervical os may indicate decidual membrane separation or subclinical membrane injury or rupture and can serve as an effective predictor of preterm birth. ${ }^{13,15}$
1-3,6Department of Obstetrics and Gynecology, King George Medical University, Lucknow, Uttar Pradesh, India

${ }^{4}$ Department of Pathology, King George Medical University, Lucknow, Uttar Pradesh, India

${ }^{5}$ Department of Obstetrics and Gynecology, Era Medical College, Lucknow, Uttar Pradesh, India

Corresponding Author: Seema Mehrotra, Department of Obstetrics and Gynecology, King George Medical University, Lucknow, Uttar Pradesh, India, Phone: +91 9918924300, e-mail: mehrotra.seema@ gmail.com

How to cite this article: Mehrotra S, Singh U, Solanki V, et al. Study of Prolactin in Cervicovaginal Secretion in Women with Preterm Labor and Normal Pregnancy. J South Asian Feder Obst Gynae 2020;12(1): 34-37.

Source of support: Nil

Conflict of interest: None

Therefore, this study was planned to evaluate the diagnostic value of cervicovaginal prolactin levels for predicting preterm delivery in women with preterm labor.

\section{Materials and Methods}

This was a prospective study of one-year duration conducted on 229 women between 24 weeks and 36 weeks of pregnancy with or without labor pains. The study was approved by the local ethics committee, and written consent was obtained after detailed information was given to every patient selected for the study.

Women with singleton gestation accurately dated by early second-trimester ultrasonographic examination with cervical dilatation $<3 \mathrm{~cm}$, intact amniotic membrane, and absence of

() The Author(s). 2020 Open Access This article is distributed under the terms of the Creative Commons Attribution 4.0 International License (https://creativecommons. org/licenses/by-nc/4.0/), which permits unrestricted use, distribution, and non-commercial reproduction in any medium, provided you give appropriate credit to the original author(s) and the source, provide a link to the Creative Commons license, and indicate if changes were made. The Creative Commons Public Domain Dedication waiver (http://creativecommons.org/publicdomain/zero/1.0/) applies to the data made available in this article, unless otherwise stated. 
other maternal and fetal complications were included in the study. Woman with fetal congenital anomaly, placenta previa, vaginal bleeding, pregnancy-induced hypertension, fetal growth restriction, fetal distress, and multiple gestation were excluded from the study.

All enrolled women were subjected to detailed history, examination, and routine antenatal investigations. Cervicovaginal secretion sample for prolactin estimation was obtained during speculum examination from all patients before digital examination of patient and prior to administration of tocolytic therapy if needed. The single sample was taken at the time of enrollment of the patients. For the control group, mean gestational age being $31 \pm 5.4$ weeks. For the study group, sample was taken at the time when patients came with symptoms and signs of preterm labor (mean gestational age for study group la: $29.4 \pm 2.2$ weeks and for study group Ib: $30.6 \pm 4.2$ weeks. A cotton tipped swab was placed just into the endocervical canal and then into the posterior fornix of vagina, each for 30 seconds, in order to obtain cervicovaginal secretion samples for prolactin assay. The swab was then placed in a tube containing $1 \mathrm{~mL}$ of saline solution, and the tube was shaken for 1 minute before the swab was disposed off. The samples were centrifuged for 5 minutes at the rate of 1500 revolutions per minute. The supernatant was quantitatively tested for the presence of prolactin. The estimation of prolactin was done by Accu-Bind (ELISA MICROWELLS) kit manufactured by Monoclonal Inc., Lake Forest, CA. The Prolactin Accu Bind ELISA test system has a sensitivity of $0.05 \mathrm{ng}$. This is equivalent to sample containing $1.0 \mathrm{ng} / \mathrm{mL}$ prolactin (PRL) concentration.

The sample size was calculated using the following formula:

$$
n=\frac{z^{2} \times p \times(1-p)}{d^{2}}
$$

where $p=0.9$ ( $90 \%$ sensitivity), $z=1.96, d=0.5$ (precision).

A total of 229 patients were followed till delivery and were divided into the following groups. Study group: patient who came up with preterm labor, tocolytics given, and then patient followed till delivery $(n=75)$. The study group was further subdivided into two groups. Study group la: patient who came up with preterm labor pain, tocolytics given but had preterm delivery $(n=50)$. Study group lb: patient who came up with preterm labor, tocolytics given, and patient delivered full term $(n=25)$. Control group: patient with normal pregnancy with no preterm labor pain $(n=154)$. They were followed till delivery. Of 154, 150 delivered at full term and 4 patients had preterm delivery. As their number was so less, they were excluded from the study. Therefore, the total number of patients analyzed was 225 (after excluding 4 patients in control group who delivered preterm).

The categorical data were described as $n(\%)$ whereas continuous variables as mean $\pm \mathrm{SD}$. Two-sample $t$ test and MannWhitney test were used in group comparisons. One-way ANOVA was used to test the difference among $>2$ groups in a case of normally distributed data. Data were analyzed using statistical software package, STATA 11.2.

The receiver operating characteristic (ROC) curve analysis was used to establish the cut-off values for cervicovaginal prolactin in the prediction of preterm delivery.

\section{Results}

The demographic and obstetric characteristics of the women enrolled in the study are shown in Table 1. There was no statistically significant difference between study group and control group with regard to maternal age, parity, body mass index, socioeconomic status, and gestational age.

Table 2 showed prolactin values obtained from cervicovaginal secretions in women delivered term or preterm. In the study group, the mean values of cervicovaginal prolactin were higher $(9.41 \pm$ $9.0 \mathrm{ng} / \mathrm{mL})$ as compared to the control group $(2.15 \pm 5.1 \mathrm{ng} / \mathrm{mL})$, and this was statistically significant $(p=0.0000)$. The study group la had the highest mean value of prolactin $(11.81 \pm 9.31 \mathrm{ng} / \mathrm{mL})$ as compared to the study group $\mathrm{lb}(4.61 \pm 6.2 \mathrm{ng} / \mathrm{mL})$ and control group $(2.15 \pm 5.1 \mathrm{ng} / \mathrm{mL})$, and the difference was statistically significant. The mean latency period from testing to delivery in the control group was $7.2 \pm 1.3$ weeks. The mean latency period from testing to delivery was significantly shorter in the study group la as compared to the study group $\mathrm{lb}(3.9 \pm 2.1$ vs $6.6 \pm 1.2$, respectively, $p<0.001$; power $=100 \%$ ).

The receiver operator characteristic curve analysis (Fig. 1) was used to establish optimal cut-off values of prolactin in the cervicovaginal secretion in order to predict preterm delivery. The optimal cut-off value of prolactin was greater than $7 \mathrm{ng} / \mathrm{mL}$ in study group la with the sensitivity level of $78 \%(64.04-88.47,95 \% \mathrm{Cl})$, at a specificity level of $80 \%(59.30-93.17,95 \% \mathrm{Cl})$ with positive and negative predictive values of $88.64 \%$ and $64.52 \%$, respectively. The area under the ROC curve was $79 \%(69.12-88.88,95 \% \mathrm{Cl})$ which indicates fair diagnostic accuracy of cervicovaginal prolactin in predicting preterm labor. The optimal cut-off value of prolactin in patients who came up with preterm labor pain, tocolysis given, and delivered full term (study group $\mathrm{lb}$ ) was $\geq 2.5 \mathrm{ng} / \mathrm{mL}$.

\section{Discussion}

Preterm delivery continues to be a leading cause of perinatal morbidity and mortality throughout the world. Recent advances

Table 1: Demographic and obstetric characteristics of study groups

\begin{tabular}{lllll}
\hline & $\begin{array}{l}\text { Control } \\
\text { group }\end{array}$ & $\begin{array}{l}\text { Study } \\
\text { group la }\end{array}$ & $\begin{array}{l}\text { Study } \\
\text { group lb }\end{array}$ & Significance \\
\hline $\begin{array}{l}\text { Maternal } \\
\text { age in year }\end{array}$ & $26.02 \pm 3.5$ & $25.20 \pm 2.2$ & $25.10 \pm 3.2$ & $\mathrm{NS}$ \\
$\begin{array}{l}\text { Parity } \\
\text { BMl }\end{array}$ & $1.72 \pm 0.8$ & $1.85 \pm 1.1$ & $1.84 \pm 0.9$ & $\mathrm{NS}$ \\
& $23.59 \pm 2.0$ & $22.28 \pm 2.6$ & $24.17 \pm 2.1$ & $\mathrm{NS}$ \\
$\mathrm{kg} / \mathrm{m}^{2}$ & $\mathrm{~kg} / \mathrm{m}^{2}$ & $\mathrm{~kg} / \mathrm{m}^{2}$ & \\
$\begin{array}{l}\text { Gestational } \\
\text { age at } \\
\text { admission }\end{array}$ & $31 \pm 5.4$ & $29.4 \pm 2.2$ & $30.6 \pm 4.2$ & $\mathrm{NS}$ \\
\hline
\end{tabular}

Table 2: Cervicovaginal prolactin values in different groups

\begin{tabular}{lrrl}
\hline Group & No. & Mean & Median \\
\hline Study group la & 50 & $11.81 \pm 9.3$ & 9.34 \\
Study group Ib & 25 & $4.61 \pm 6.2$ & 2.00 \\
Control & 150 & $2.15 \pm 5.1$ & 0.90 \\
Total & 225 & $4.75 \pm 7.5$ & 1.10 \\
\hline
\end{tabular}




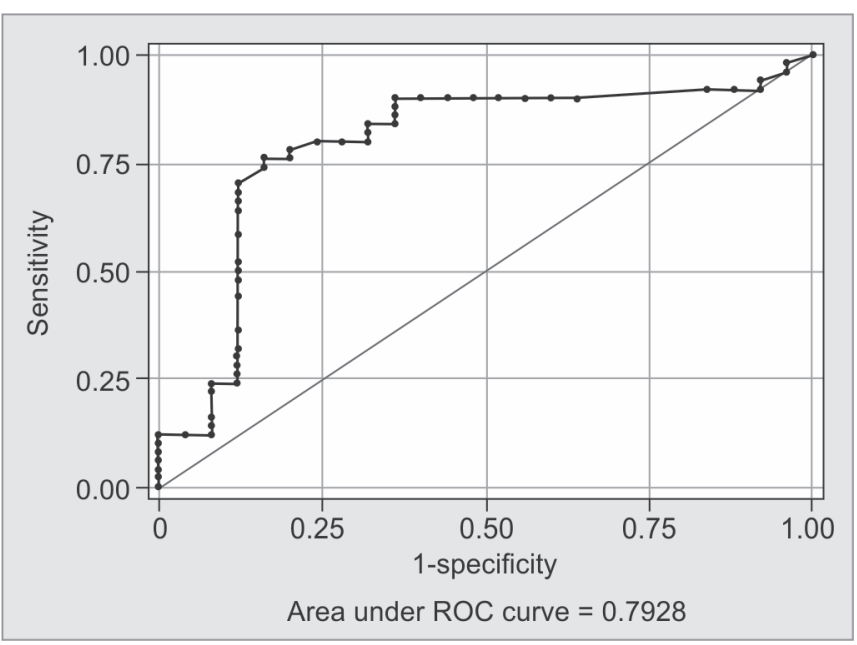

Fig. 1: ROC curve for prolactin for the prediction of preterm delivery

in perinatal healthcare have markers that facilitated more accurate prediction of preterm birth. The use of biological marker to enhance clinical approach in predicting preterm birth has been recently proposed. These tests have high potential to identify these symptomatic and asymptomatic patients who are at greater risk for preterm birth and who subsequently may require more intensive observation and interventions in terms of tocolysis and therapy for fetal lung maturation. Conversely, if low risk of preterm birth is diagnosed, the need for aggressive tocolysis, prolonged hospitalization, and close follow-up visits may be reduced. Till date, several biochemical markers have been studied but none have proved to be a gold standard.

In the present study, we have evaluated the diagnostic value of prolactin in the cervicovaginal secretion for predicting preterm delivery in women with preterm labor and in normal pregnancies. Prolactin was the first of many hormones recognized as a product of human decidualized endometrium. ${ }^{14}$ Prolactin is present in high concentration in amniotic fluid and may leak into the vagina following disruption of the decidua membrane interface which precedes onset of preterm labor. ${ }^{13}$ In our study, we observed that mean prolactin level in the women with preterm labor was three times higher than in control group $(9.41 \pm 9 \mathrm{mlU} / \mathrm{mL}$ vs $2.15 \pm 51$ $\mathrm{mlU} / \mathrm{mL}$ ), and the difference was statistically significant $(p=0.000)$. Our results were in good agreement with the study of $\mathrm{O}^{\prime}$ Brien et al. ${ }^{15}$ and Guvenal et al. ${ }^{16}$

$\mathrm{O}^{\prime}$ Brien et al. ${ }^{15}$ reported that prolactin was significantly identified in more women with preterm labor than in asymptomatic controls (50\% vs 5\%; $p<0.0001)$. Similarly, Guvenal et al. ${ }^{16}$ found significantly higher levels of prolactin in preterm group as compared to term delivery group $(2.2 \pm 17 \mathrm{mlU} / \mathrm{mL}$ vs $0.83 \pm 0.66 \mathrm{mlU} / \mathrm{mL}$, respectively, $p=0.026$ ).
$\mathrm{O}^{\prime}$ Brien et al. ${ }^{15}$ also observed that patients testing positive for prolactin had significantly shorter latency from testing to delivery ( $16 \pm 17$ vs $34 \pm 24$ days, $p=0.02$ ) compared with patients testing negative. This was in concurrence to our study where patients with high prolactin levels delivered preterm despite tocolytic therapy.

The cut-off value of the cervicovaginal prolactin levels in prediction of preterm delivery in our study was greater than $7 \mathrm{ng} /$ $\mathrm{mL}$. The sensitivity, specificity, positive and negative predictive values of cervicovaginal prolactin for predicting preterm delivery were $78 \%, 80 \%, 88.64 \%$, and $64.52 \%$, respectively.

These values are high as compared to other studies (Table 3). O'Brien et al. ${ }^{15}$ gave the cut-off values greater than $2 \mathrm{ng} / \mathrm{mL}$, positive predictive values of $80 \%$, and negative predictive values of $65 \%$ in symptomatic patient with cervicovaginal secretion for delivery $\leq 34$ weeks gestation. Prolactin values greater than $1.8 \mathrm{ng} / \mathrm{mL}$ when considered positive in the study of 17 women with preterm labor by Guvenal et al. ${ }^{16}$ According to these values, the sensitivity, specificity, positive and negative predictive values of the cervicovaginal prolactin for predicting preterm delivery were $50 \%, 96 \%, 67 \%$, and $93 \%$, respectively. Guvenal et al. also reported that cervicovaginal prolactin $>1.8 \mathrm{ng} / \mathrm{mL}$ can identify $50 \%$ of women who will deliver preterm. Also, because of high negative predictive value of cervicovaginal prolactin for predicting preterm labor, unnecessary hospitalization and manipulative procedures can be avoided.

The other studies evaluated vaginal prolactin concentration in women with suspected but unconfirmed premature rupture of membrane. Buyukbayrak et al. ${ }^{17}$ and Kariman et al. ${ }^{18}$ gave the cut-off value of $30 \mu \mathrm{lU} / \mathrm{mL}$ and $9.5 \mu \mathrm{lU} / \mathrm{mL}$, respectively, for vaginal washings prolactin in detecting premature rupture of membranes.

In the present study, we have observed that the cut-off values of prolactin in patients who came up with preterm labor pain, tocolysis given, and delivered at full term (study group lb) was $\geq 2.5 \mathrm{ng} / \mathrm{mL}$.

The difference in the sensitivity and specificity of various studies could be due to differences in the methodology used. Also, variation in the inclusion and exclusion criteria used and the characteristics of the patients studied (high or low risk for preterm delivery) can affect the cut-off value, sensitivity, and specificity of the cervicovaginal secretion prolactin for predicting preterm labor.

Also, we suggest that patients with preterm labor having a cut-off value of prolactin between 2.5 and $7 \mathrm{ng} / \mathrm{mL}$ are the highrisk group and need close monitoring and early intervention in the form of prophylactic tocolysis to prevent them from going into preterm labor.

Use of cervicovaginal prolactin as a biochemical marker has certain disadvantage. While the prolactin test appears to be informative in women with threatened preterm labor, it is generally poor positive predictive values ${ }^{15,16,18}$ and external factors (e.g., amniotic fluid contamination, vaginal bleeding, and unprotected sexual intercourse) that may limit its use as a lone predictor of preterm labor. Besides this, the method for collecting cervicovaginal

Table 3: Comparison of predictive values of cervicovaginal prolactin in published literatures

\begin{tabular}{|c|c|c|c|c|c|}
\hline Studies & $\begin{array}{l}\text { Cut-off value cervicovaginal } \\
\text { prolactin }(\mathrm{ng} / \mathrm{mL})\end{array}$ & Sensitivity (\%) & Specificity (\%) & PPV (\%) & $N P V(\%)$ \\
\hline O'Brien et al., $1994^{15}$ & $>2$ & 88 & 79 & 80 & 65 \\
\hline Guvenal et al., $2001^{16}$ & 1.8 & 50 & 96 & 67 & 93 \\
\hline Buyukbayrak et al., $2004^{17}$ & 30 & 95 & 78 & 93 & 84 \\
\hline Kariman et al., $2012^{18}$ & 9.5 & 87.03 & 75 & 75.80 & 86.53 \\
\hline Present study, 2018 & $>7$ & 80 & 80 & 88.64 & 64.52 \\
\hline
\end{tabular}


sample may also influence the results. ${ }^{9}$ Therefore, well-defined and standardized sampling methods for cervicovaginal prolactin may help avoiding misinterpretation of results and decrease the variations in the values due to technical differences in the experimental set-up.

On the other hand, cervicovaginal prolactin can be used clinically for its negative predictive value, which reaches $93 \%$ in some studies ${ }^{16}$ and will be particularly useful in determining whether a symptomatic patient in remote region requires emergency transfer to a tertiary healthcare facility.

Despite variations in the cut-off values of different studies, the significant point is that the raised cervicovaginal prolactin levels in women are at risk of preterm labor, and it can serve as a useful test for predicting preterm labor.

Our study has some limitations. The major drawback is the small sample size. Second, the samples were collected at the time when the patient had come with preterm labor. The definitive role of a biochemical marker can be ascertained only on evaluating their role in predicting the disease in high-risk population. Hence, a prospective study evaluating these biomarkers in early pregnancy and then following them for the development of preterm labor is imperative to substantiate these findings. This will facilitate the initiation of therapeutic interventions for maternal and fetal wellbeing in early pregnancy.

\section{Conclusion}

The data from this study suggest that prolactin is a potential biochemical marker which can be used for predicting preterm labor. Because of the multifaceted etiology of preterm birth, the desired predictive efficacy with single biochemical marker appears unlikely. Therefore, multiple biomarker modelling is suggested to predict preterm labor. The poor positive predictive value of cervicovaginal prolactin limits its role as a single marker to predict preterm labor. For this reason, we suggest that prolactin can be used simultaneously with other markers such as demographic/risk factors, cervical length, and other biochemical markers to improve diagnostic efficiency.

\section{References}

1. Lawn JE, Wilczynska-Ketende K, Cousens SN. Estimating the causes of 4 million neonatal deaths in the year 2000. Int J Epidemiol 2006;35(3):706-718. DOI: 10.1093/ije/dyl043.

2. Petrou S, Mehta Z, Hockley C, et al. The impact of pretum birth on hospital inpatient admissions and casts during the first 5 years of life. Peadiatrics 2003;112(6 Pt 1):19290-19297.
3. Petrou S. The economic consequences of preterm birth during the first 10 years of life. BJOG 2005;112(Suppl 1):10-15. DOI: 10.1111/j.14710528.2005.00577.x.

4. Beck S, Wojdyla D, Say L, et al. The worldwide incidence of preterm birth. A systematic review of maternal mortality and mobidity. WHO Bull 2010;88(1):31-38.

5. WHO collaborating centre for training and research in newborn care. National neonatal perinatal database network. National neonatal perinatal- database report 2002-2003. India National neonatology forum NNPD network; 2005.

6. Florio $\mathrm{P}$, Linton EA, Torricellie $\mathrm{M}$, et al. Prediction of preterm delivery based on maternal plasma Urocortin. J Clin Endocrinol Metab 2007;92(12):4734-4737. DOI: 10.1210/jc.2007-0457.

7. Malak TM, Sizmer F, Bell SC, et al. Fetal fibronectin in cervicovaginal secretions as a prediction of preterm birth. BJOG 1996;10(7):648-653. DOI: 10.1111/j.1471-0528.1996.tb09832.x.

8. Paternoster DM, Muresan D, Vitul A, et al. Cervical phIGFBP-1 in the evaluation of the risk of preterm delivery. Acta Obstet Gynecol Scand 2007;86(2):151-155. DOI: 10.1080/00016340600935730.

9. Zegels G, Van Raemdonck GAA, Tjalma WAA, et al. Use of cervicovaginal fluid for the identification of biomarkers for pathologies of the female genital tract. Proteome Sci 2010;8:63. DOI: 10.1186/1477-5956-8-63.

10. Anai T, Tanakay, Hirota Y, et al. Vaginal fluid HCG levels for detecting premature rupture of membranes. Obstet Gynecol 1997;89(2): 261-264. DOI: 10.1016/S0029-7844(96)00448-6.

11. Leitich $\mathrm{H}$, Egartu C, Kaider A, et al. Cervicovaginal fetal fibronectin as a marker for preterm delivery: a meta analysis. Am J obstet Gynecol 1999;180(5):1169-1176. DOI: 10.1016/S0002-9378(99)70612-5.

12. Maaskant RA, Bogic LV, Gilger S, et al. The human prolactin receptor in the fetal membranes, decidua and placenta. J Clin Endocrinol Metab 1996;81(1):396-405. DOI: 10.1210/jcem.81.1.8550784.

13. Hauth JC, Parker Jr. CR, Mac Donald PC, et al. A role of fetal prolactin in lung maturation. Obstect Gynecol 1978;51(1):81-88. DOI: 10.1097/00006254-197808000-00002.

14. Riddick DH, Luciano AA, Kusmik W, et al. De novo synthesis of prolactin by human decidua. Life Sci 1978;23(19):1913-1921. DOI: 10.1016/0024-3205(78)90557-X.

15. O' Brien JM, Peeler G, Pitts DW, et al. Cervicovaginal prolactin: a marker for spontaneous preterm delivery. Am obstet Gynecol 1994;171(4):1107-1111. DOI: 10.1016/S0002-9378(13)90045-4.

16. Guvenal T, Kantas E, Erselcan T, et al. Beta-human chronic gonadotrophs and prolactin assays in cervicovaginal secretions as a predictor of preterm delivery. Int J Gynaecol Obstet 2001;75(3): 229-234. DOI: 10.1016/S0020-7292(01)00495-7.

17. BuyukbayrakEE, Turan C, Unal O, et al. Diagnostic power of the vaginal washing -fluid prolactin assay as an alternative method for the diagnosis of premature rupture of membranes.J Matern Fetal Neonatal Med 2004;15(2):120-125. DOI: 10.1080/14767050410001659842.

18. Kariman N, Hedayati M, Majd SHA. The role of vaginal prolactin in diagnosis of premature rupture of membranes. Acta obstet Gynecol Scand 2005;84(8):802-805. 